\title{
NOS inhibitors exhibit antinociceptive properties in the rat formalin test
}

\author{
[Les inbibiteurs de NOS affichent des propriétés antinociceptives an test de
}

formaline chez des rats]

Marie-Françoise Doursout PhD, Yangyan Liang MD, Jacques E. Chelly MD PhD MBA

Purpose: To assess the systemic and nociceptive effects of nitric oxide synthase (NOS) inhibitors in the modulation of acute pain in rats subjected to the formalin test.

Methods: Formalin 5\% was injected in the hind paw in the presence and absence of NOS inhibitors (e.g., 7-nitro indazole, Nnitro-L-arginine and aminoguanidine). Catheters were chronically implanted to continuously record mean arterial blood pressure (MAP) and heart rate (HR). MAP, HR and paw lifting time were recorded at control and every five minutes for $35 \mathrm{~min}$ following formalin and NOS inhibitors.

Results: Formalin injected into the rat hind paw induced a biphasic nociceptive behaviour: an initial acute phase (phase I: during zero to five minutes after the formalin injection) followed by a prolonged tonic response (phase 2: beginning about ten minutes after the formalin injection). Aminoguanidine, an inhibitor of the inducible NOS and 7-nitro indazole, an inhibitor of the neuronal NOS, did not affect phase I, whereas N-nitro-L-arginine, a non-selective NOS inhibitor decreased it (49\%). All three NOS inhibitors diminished nociceptive behaviours during phase 2. L-arginine reversed antinociceptive effects of $\mathrm{N}$-nitro-L-arginine in phase I and in phase 2. Pressor effects induced by formalin in phase I were abolished following all three NOS inhibitors. During phase 2, formalininduced pressor effects remained unaffected by $\mathrm{N}$-nitro-L-arginine and aminoguanidine but were inhibited by 7 -nitro indazole.

Conclusion: Our data demonstrate that $\mathrm{NO}$ is predominantly generated by vascular endothelial NOS in phase I and phase 2 , whereas the neuronal NOS and the inducible NOS exhibit antinociceptive effects through a non- $\mathrm{NO}$ related pathway in phases $I$ and 2 in rats subjected to the formalin test.
Objectif : Évaluer les effets généraux et nociceptifs des inhibiteurs de la nitric oxide synthase (NOS) dans la modulation de la douleur aiguë chez des rats soumis au test de formaline.

Méthode : De la formaline à $5 \%$ a été injectée dans la patte arrière de rats en présence ou non d'inhibiteurs de NOS (par ex., 7-nitro indazole, N-nitro-L-arginine et aminoguanidine). Des cathéters ont été implantés à demeure pour permettre l'enregistrement continu de la tension artérielle moyenne (TAM) et de la fréquence cardiaque (FC). La TAM, la FC et le temps d'élévation de la patte ont été notés au temps témoin et aux cinq minutes pendant 35 min après l'administration de formaline et d'inhibiteurs de NOS.

Résultats : La formaline injectée dans la patte arrière des rats a induit un comportement nociceptif biphasique : une phase aiguë initiale (phase I : de zéro à cinq minutes après l'injection de formaline) suivie d'une réponse tonique prolongée (phase 2 : débutant environ dix minutes après l'injection de formaline). L'aminoguanidine, un inhibiteur de la NOS inductible et le 7-nitro indazole, un inhibiteur de la NOS neuronale, n'ont pas modifié la phase I, tandis que la N-nitro-L-arginine, un inhibiteur de NOS non sélectif, a réduit la phase I (49\%). Les trois inhibiteurs de NOS ont diminué les comportements nociceptifs pendant la phase 2. La L-arginine a renversé les effets antinociceptifs de la N-nitro-L-arginine pendant les phases I et 2. Les effets vasopresseurs induits par la formaline en phase I ont été abolis à la suite de l'injection des trois inhibiteurs de NOS. Pendant la phase 2, les effets vasopresseurs induits par la formaline n'ont pas été modifiés par la N-nitro-L-arginine et l'aminoguanidine, mais ont été inhibés par le 7-nitro indazole.

Conclusion : Nos résultats démontrent que le NO est généré surtout par la NOS endothéliale vasculaire en phases I et 2, tandis que les NOS neuronale et inductible présentent des effets antinociceptifs par un mécanisme non relié au NO en phases I et 2 chez des rats soumis au test de formaline.

From the Department of Anesthesiology, The University of Texas Medical School at Houston, Houston, Texas, USA.

Address correspondence to: Dr. Jacques E. Chelly, Department of Anethesiology, University of Pittsburgh School of Medicine, 3550

Terrace Street, A-1305 Scaife Hall, Pittsburgh, Pennsylvania 15261, USA. Phone: 412-648-9560; Fax: 412-648-1887;

E-mail: chelje@anes.upmc.edu

Work was performed at The University of Texas Medical School at Houston, Department of Anesthesiology.

Accepted for publication January 28, 2003.

Revision accepted July 21, 2003. 
$\mathrm{R}$ ECENT research has centered upon the part played by nitric oxide $(\mathrm{NO})$ in the mechanism of pain. $\mathrm{NO}$, first discovered as a potent vasodilatator produced by the vascular endothelium, is now recognized as the transduction mechanism responsible for activating soluble guanylate cyclase and has been demonstrated in a wide variety of tissue types, including the central nervous system (CNS). ${ }^{1} \mathrm{NO}$ synthase (NOS), which is responsible for the formation of NO from L-arginine, exists in mammalian cells as three structurally distinct isoforms namely endothelial, neuronal, and inducible NOS.

$\mathrm{NO}$ is involved in the transmission and modulation of nociceptive information at the periphery, spinal cord and supraspinal level. ${ }^{2}$ Experimentally, several models of pain have been developed. Among them are the awake rats subjected to the formalin test. ${ }^{3-5}$ The formalin test model produces a biphasic response: the early nociceptive response, possibly related to $\mathrm{C}$ fibre activation and the late nociceptive response, which appears to be dependent on a combination of inflammatory reactions in the peripheral tissue and facilitation of spinal transmission. ${ }^{6,7}$ Formalin injection into the plantar surface of the hind paw induces nociceptive behaviour, and this formalininduced agitation behaviour has been used as a model for animal pain. ${ }^{8}$ Recently, it has been reported that NOS inhibitors depressed the agitation behaviour when administered by topical application, ${ }^{9}$ intrathecally ${ }^{10,11}$ intraperitoneally, ${ }^{2}$ intracerebroventricularly or orally. ${ }^{2}$ However, studies on the peripheral role of the NO pathway involved in the mechanism of hyperalgesia have been limited. Although NOS inhibitors apparently have little or no effect on nociceptive transmission under normal conditions, ${ }^{12}$ there is ample evidence that peripheral inflammation and/or CNS injury increases NOS activity that in turn may underlie numerous abnormal pain-related sensations. ${ }^{13-15}$

Thus, this study was designed to assess the systemic effects of NOS inhibitors e.g., N-nitro-L-arginine, as a non-selective NOS inhibitor, ${ }^{16}$ also reported to cause hypertension, ${ }^{17}$ aminoguanidine, as a specific inhibitor of inducible $\mathrm{NOS}^{18}$ and 7-nitro indazole, as a specific inhibitor of neuronal $\mathrm{NOS}^{19}$ in the presence and in the absence of $\mathrm{L}$-arginine, the precursor of $\mathrm{NO}$ synthesis, in the modulation of acute pain and the associated cardiovascular changes in awake rats subjected to the formalin test.

\section{Materials and methods}

\section{Cardiovascular instrumentation}

After approval from the Animal Welfare Committee of the University of Texas Medical School, Sprague Dawley rats (300-350 g) were anesthetized with $2 \%$ halothane, intubated and ventilated under isothermic conditions. Tygon PE-50 catheters [internal diameter (ID): $0.020 \mathrm{~mm}$; outer diameter (OD): $0.060 \mathrm{~mm}$ Tygon, Cole-Parmer Instrument Co., Chicago, IL, USA] were introduced into the abdominal aorta via the femoral artery to record arterial blood pressure (BP) and heart rate (HR) and into the femoral vein for drug administrations. Catheters were tunnelled to the dorsum of the neck for externalization and the surgical wounds were closed. Buprenorphine in a dose of 0.01 to $0.02 \mathrm{mg} \cdot \mathrm{kg}^{-1}$ was administered subcutaneously on one occasion at the end of surgery. Antibiotic therapy (gentamycin $5 \mathrm{mg} \cdot \mathrm{kg}^{-1}$, administered intramuscularly) was initiated for five days postoperatively. To avoid damage to the implanted catheters, animals were housed in individual cages in an air-conditioned, light controlled room ( $12 \mathrm{hr}$ light, $12 \mathrm{hr}$ dark) and were allowed to mobilize freely. The animals recovered from surgery for at least five days before initiation of the experimental protocol.

\section{Experimental design}

Animals of all groups were placed on a metal mesh screen $(20 \mathrm{~cm} \times 20 \mathrm{~cm})$. Rats were divided into six groups. Group 1 received N-nitro-L-arginine at 1 $\mathrm{mg} \cdot \mathrm{kg}^{-1} i v$ bolus, in the presence $(n=8)$ and in the absence of L-arginine $(n=8)$; Group 2 received aminoguanidine, at $30 \mathrm{mg} \cdot \mathrm{kg}^{-1}$ iv bolus in the presence $(n=8)$ and in the absence of L-arginine $(n=8)$; Group 3 received 7 -nitro-indazole at $50 \mathrm{mg} \cdot \mathrm{kg}^{-1}$ ip bolus in the presence $(n=8)$ and in the absence of Larginine $(n=8)$; Group $4(n=6)$ received L-arginine alone at $\mathrm{l} \mathrm{g} \cdot \mathrm{kg}^{-1}$ over one minute, iv whereas Group $5(n=8)$ received saline and served as the control.

To eliminate the possibility that the pressor effects of $\mathrm{N}$-nitro-L-arginine contributed to analgesia, we assessed the effects of phenylephrine, an $\alpha_{1}$-adrenoceptor agonist administered in a dose of 50 $\mathrm{mg} \cdot \mathrm{kg}^{-1} \cdot \mathrm{min}^{-1} i v$, on BP and nociceptive behaviours (Group $6 ; n=5$ ). The doses of NOS inhibitors and Larginine were chosen based on data previously reported by Gardiner et al. in 1990 in awake rats. ${ }^{17}$

To evaluate paw edema in response to formalin injection, we measured the plantar circumference of the formalin-injected paw with a thread to the nearest millimetre according to the method of Eschalier et al. ${ }^{20}$

Maximum effects (steady-state) following NOS inhibitors or saline administration occur within 30 min. When steady-state was achieved, formalin 5\% (30 $\mu \mathrm{L}$ ) was injected at the plantar surface of the rat hind paw with a 28 -gauge needle attached to a $50-\mu \mathrm{L}$ Hamilton syringe (PGC Scientifics, Frederick, MD, USA) with PE-10 tubing (ID: $0.28 \mathrm{~mm}$; OD: 0.61 
TABLE I

\begin{tabular}{|c|c|c|c|c|}
\hline & Saline & 7-nitro indazole & $N$-nitro-L-arginine & Aminoguanidine \\
\hline Phase 1 & $244 \pm 24$ & $204 \pm 23$ & $159 \pm 27^{*}$ & $188 \pm 22$ \\
\hline \multirow[t]{3}{*}{ Phase 2} & $835 \pm 74$ & $563 \pm 74^{*}$ & $514 \pm 95 *$ & $204 \pm 32$ * \\
\hline & L-arginine & 7-nitro indazole & $\mathrm{N}$-nitro-L-arginine & Aminoguanidine \\
\hline & $+\mathrm{L}$-arginine & $+\mathrm{L}$-arginine & $+\mathrm{L}$-arginine & $+\mathrm{L}$-arginine \\
\hline Phase 1 & $398 \pm 72$ & $30 \pm 16^{*}$ & $256 \pm 57$ & $18 \pm 10^{*}$ \\
\hline Phase 2 & $1036 \pm 180$ & $59 \pm 39 *$ & $770 \pm 159$ & $39 \pm 21$ * \\
\hline
\end{tabular}

Maximum effects of 7-nitro indazole, $\mathrm{N}$-nitro-L-arginine and aminoguanidine in the presence and in the absence of $\mathrm{L}$-arginine on paw lifting time (seconds) in rats subjected to the formalin test. Data are expressed as mean \pm SEM. $P<0.05$ vs saline and L-arginine.

TABLE II

\begin{tabular}{|c|c|c|c|}
\hline & & Baseline & Steady state \\
\hline \multirow[t]{2}{*}{ Saline } & $\mathrm{MAP}(\mathrm{mmHg})$ & $112 \pm 3$ & $111 \pm 4$ \\
\hline & $\mathrm{HR}$ (beats. $\mathrm{min}^{-1}$ ) & $384 \pm 10$ & $378 \pm 9$ \\
\hline \multirow[t]{2}{*}{$\mathrm{N}$-nitro-L-arginine } & $\mathrm{MAP}(\mathrm{mmHg})$ & $109 \pm 2$ & $125 \pm 8^{*}$ \\
\hline & $\operatorname{HR}$ (beats. $\mathrm{min}^{-1}$ ) & $376 \pm 7$ & $356 \pm 10^{*}$ \\
\hline \multirow[t]{2}{*}{ 7-nitro indazole } & $\mathrm{MAP}(\mathrm{mmHg})$ & $110 \pm 2$ & $113 \pm 1$ \\
\hline & $\mathrm{HR}$ (beats. $\mathrm{min}^{-1}$ ) & $367 \pm 9$ & $351 \pm 8^{*}$ \\
\hline \multirow[t]{2}{*}{ Aminoguanidine } & $\mathrm{MAP}(\mathrm{mmHg})$ & $109 \pm 2$ & $115 \pm 4$ \\
\hline & HR (beats. $\mathrm{min}^{-1}$ ) & $390 \pm 6$ & $350 \pm 13^{*}$ \\
\hline
\end{tabular}

Effects of saline $(n=8)$, N-nitro-L-arginine $(n=8), 7$-nitro-indazole $(n=8)$ and aminoguanidine $(n=8)$ on mean arterial blood pressure (MAP) and heart rate (HR) prior to drug administration (baseline) and at steady state (before formalin injection). Data are expressed as mean \pm SEM. ${ }^{*} P<005$ vs baseline.

TABLE III

\begin{tabular}{|c|c|c|c|}
\hline & & Baseline & Steady state \\
\hline \multirow[t]{2}{*}{ L-arginine } & MAP (mmHg) & $109 \pm 3$ & $114 \pm 4$ \\
\hline & HR (beats. $\min ^{-1}$ ) & $360 \pm 4$ & $369 \pm 10$ \\
\hline \multirow[t]{2}{*}{$\mathrm{N}$-nitro-L-arginine $+\mathrm{L}$-arginine } & $\mathrm{MAP}(\mathrm{mmHg})$ & $117 \pm 3$ & $111 \pm 4$ \\
\hline & HR (beats $\cdot \mathrm{min}^{-1}$ ) & $397 \pm 12$ & $435 \pm 13$ \\
\hline \multirow[t]{2}{*}{ 7-nitro indazole $+\mathrm{L}$-arginine } & $\mathrm{MAP}(\mathrm{mmHg})$ & $117 \pm 2$ & $106 \pm 6$ \\
\hline & $\mathrm{HR}$ (beats. $\mathrm{min}^{-1}$ ) & $389 \pm 133$ & $443 \pm 15^{*}$ \\
\hline \multirow[t]{2}{*}{ Aminoguanidine + L-arginine } & $\mathrm{MAP}(\mathrm{mmHg})$ & $128 \pm 5$ & $121 \pm 10$ \\
\hline & HR (beats. $\mathrm{min}^{-1}$ ) & $390 \pm 6$ & $440 \pm 9^{*}$ \\
\hline
\end{tabular}

Effects of L-arginine alone $(n=8)$ and $\mathrm{N}$-nitro-L-arginine $(n=8), 7$-nitro indazole $(n=8)$ and aminoguanidine $(n=8)$ on mean arterial pressure (MAP) and heart rate (HR) prior to drug administration (baseline) and at steady state (before formalin injection) in rats treated with $\mathrm{L}$-arginine. Data are expressed as mean \pm SEM. ${ }^{*} P<005$ vs baseline.

mm Becton-Dickinson, Sparks, MD, USA). Systolic and diastolic arterial BP were recorded with a P50 Statham pressure transducer (Gould, Cleveland, $\mathrm{OH}$, USA) connected to the PE-50 arterial catheter. Mean arterial blood pressure (MAP) was electronically derived and simultaneously displayed. HR was continuously recorded with a Gould tachometer (Gould, Cleveland, OH, USA) that was triggered by a differential arterial pressure signal. Baseline MAP and HR measurements were recorded at least $30 \mathrm{~min}$ following acclimation and before the initiation of the experiment. MAP and HR were collected at five-minute intervals for $35 \mathrm{~min}$ following the formalin injection. The femoral vein was connected to a syringe driver (Medfusion, Medex, Inc., Duluth, GA, USA) from the PE-50 tubing and used for drug administration. Formalin-induced nociceptive behaviours were assessed by an observer blinded to group assignment. Formalin injected into the rat hind paw induced a biphasic lifting behaviour. An initial acute phase (phase 1: during zero to five minutes after the formalin injection) followed by a prolonged tonic response (phase 2: beginning about ten minutes after the formalin injection). Thus, to quantify the formalin responses, the instances of spontaneous paw lifting time was counted at zero to five minutes and at fiveminute intervals during ten to $35 \mathrm{~min}$ after formalin injection. For data analysis, phase 1 and phase 2 were examined separately. Observations were carried out for a period of $35 \mathrm{~min}$ after formalin injection. 


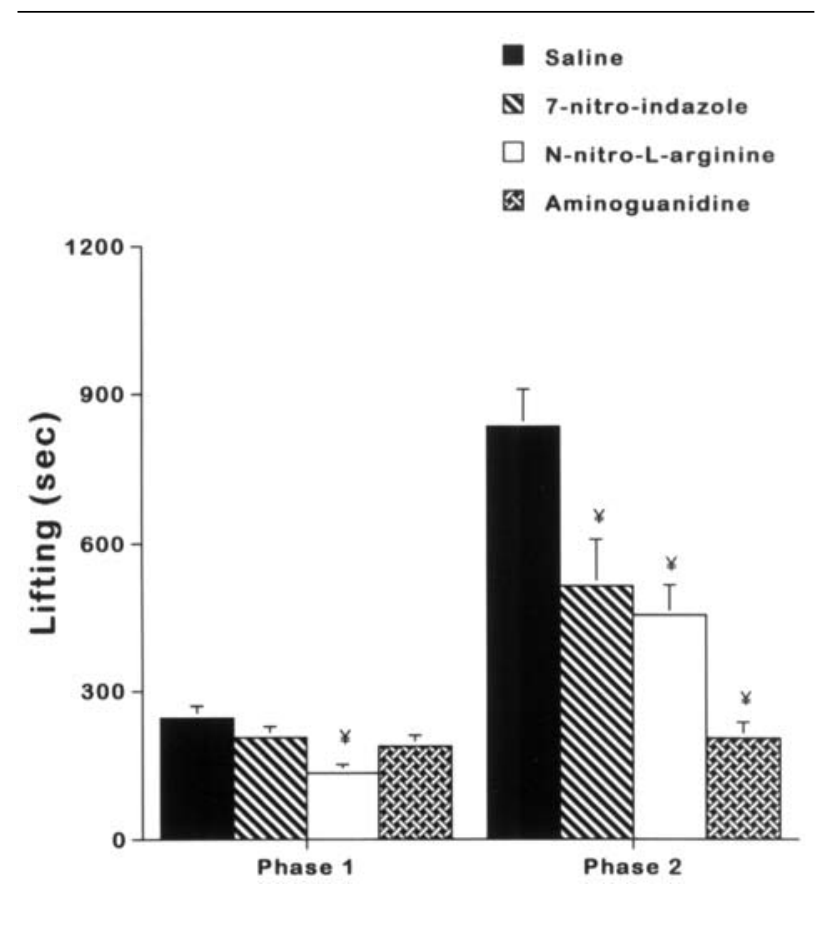

FIGURE 1 Cumulative paw lifting time in (early, 0-5 min) phase 1 and paw lifting time in (late, $10-35 \mathrm{~min}$ ) phase 2 following saline $(n=8), 7$-nitro indazole $(n=8), \mathrm{N}$-nitro-L-arginine $(n$ $=8)$ and aminoguanidine $(n=8)$ in rats subjected to formalin injection. $¥ P<0.05$ vs saline.

\section{Statistical analysis}

Hemodynamic and nociceptive changes between groups were analyzed by a one-way analysis of variance. When significant, an appropriate multiple comparison method (Dunnett's t test) was applied. In addition, a paired $t$ test was performed between baseline and steady-state in each group. All values are presented as mean \pm standard error of the mean (SEM). $P<0.05$ was considered significant.

\section{Results}

No behaviour changes occurred following N-nitro-Larginine, aminoguanidine, 7-nitro indazole or saline treatments. Upon completion of the study, all rats had normal stepping and righting reflexes.

\section{Nociceptive scoring}

Table I summarizes the effects of NOS inhibitors in the presence and in the absence of L-arginine in rats subjected to the formalin test. Subcutaneous injection of formalin resulted in two-phase nociceptive behaviours in all groups. In the primary phase (phase 1), the response was immediate and lasted up to five minutes
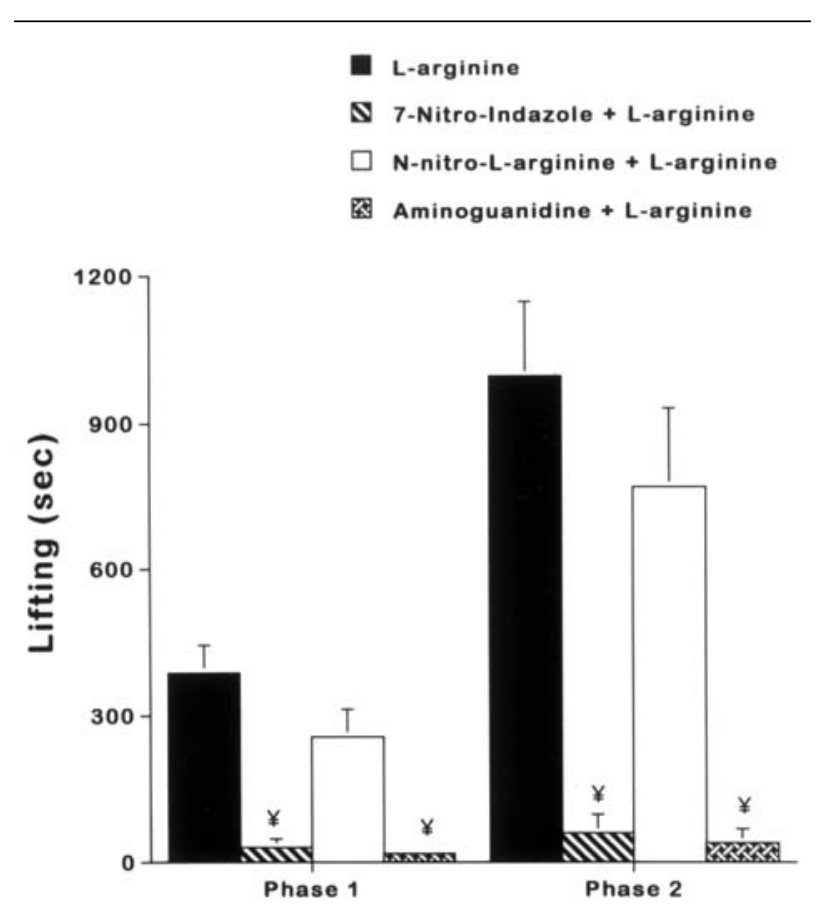

FIGURE 2 Cumulative paw lifting time in (early, $0-5 \mathrm{~min}$ ) phase 1 and paw lifting time in (late, $10-35 \mathrm{~min}$ ) phase 2 following L-arginine alone $(n=8), 7$-nitro indazole $(n=8)$, N-nitro-Larginine $(n=8)$ and aminoguanidine $(n=8)$ in L-arginine treated rats subjected to formalin injection. $¥ P<0.05$ vs L-arginine.

following formalin injection whereas phase 2 lasted 30 to $35 \mathrm{~min}$. Figure 1 represents cumulative paw lifting time in (early, zero to five minutes) phase 1 and in (late, ten to $35 \mathrm{~min}$ ) phase 2 in animals treated with saline, 7-nitro indazole, $\mathrm{N}$-nitro-L-arginine and aminoguanidine following the formalin administration. The administration of aminoguanidine and 7nitro indazole did not affect paw lifting time in phase $\mathrm{l}$ whereas $\mathrm{N}$-nitro-L-arginine significantly decreased by $50 \%$ paw lifting time in phase 1 following formalin injection. In contrast, paw lifting time was significantly diminished in the presence of 7-nitro indazole by $33 \%$, N-nitro-L-arginine by $38 \%$ and aminoguanidine by $76 \%$ during phase 2 .

Figure 2 represents cumulative paw lifting time following NOS inhibitors co-administered with L-arginine in rats subjected to formalin administration. $\mathrm{L}$-arginine reversed the antinociceptive effect of $\mathrm{N}$ nitro-L-arginine in phase 1 by $32 \%$ and in phase 2 by $25 \%$. However, the inhibition of nociceptive behaviour effects induced by 7-nitro indazole and aminoguanidine was more pronounced in the presence of $\mathrm{L}$-arginine in phase 1 by $92 \%$ and $95 \%$ and in 

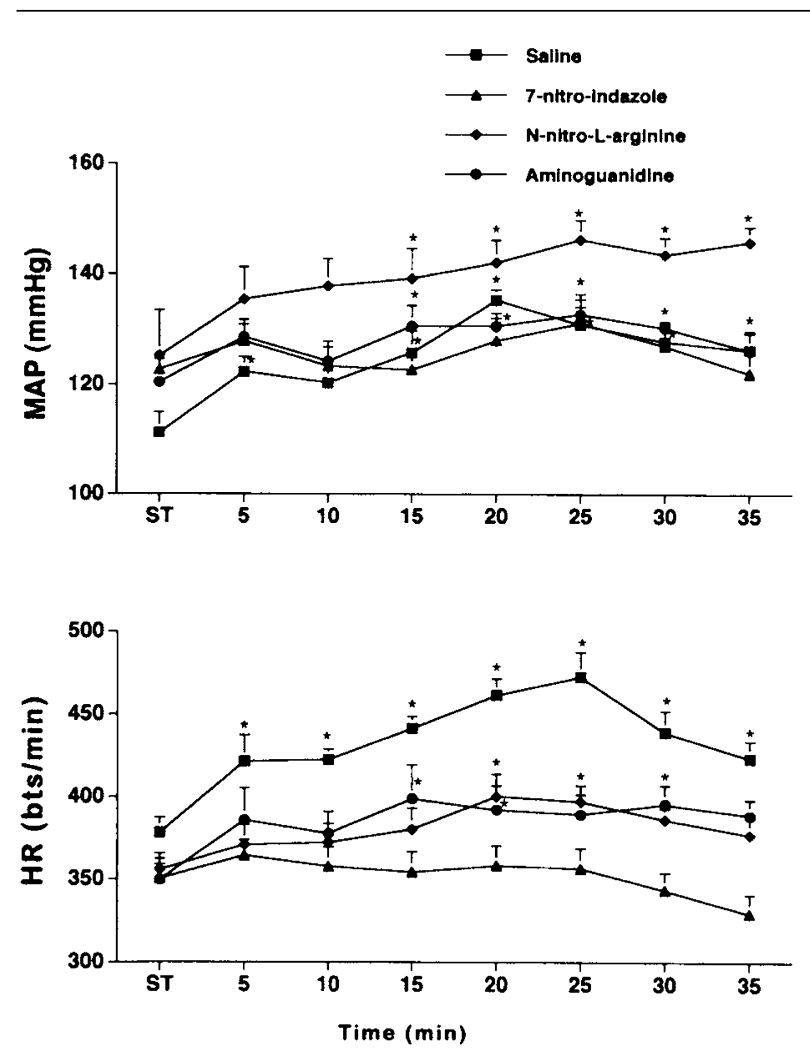

FIGURE 3 Mean arterial blood pressure and heart rate changes following saline $(n=8), 7$-nitro indazole $(n=8)$, N-nitro-L-arginine $(n=8)$ and aminoguanidine $(n=8)$ in rats subjected to formalin injection. Data are expressed as actual changes from steady state $(\mathrm{ST}$; mean $\pm \mathrm{SEM}) .{ }^{*} P<0.05$ vs ST.

phase 2 by $94 \%$ and $96 \%$, respectively. Compared with saline administration, L-arginine administered in a dose of $1 \mathrm{~g} \cdot \mathrm{kg}^{-1}$ over one minute in the absence of NOS inhibitors produced similar nociceptive responses following formalin administration.

\section{Cardiovascular measurements}

Table II represents MAP and HR before and at steady-state following administrations of saline, $\mathrm{N}$ nitro-L-arginine, aminoguanidine and 7-nitro indazole. Compared with saline-treated animals, $\mathrm{N}$-nitro-L-arginine induced a significant increased in MAP. Table III represents MAP and HR before and at steady-state following L-arginine alone, $\mathrm{N}$-nitro-Larginine, aminoguanidine and 7-nitro indazole in the presence of L-arginine.

As illustrated in Figure 3, formalin administrated in control animals induced a biphasic increase in MAP, significant at five minutes (phase 1) and at 15, 20, 25,
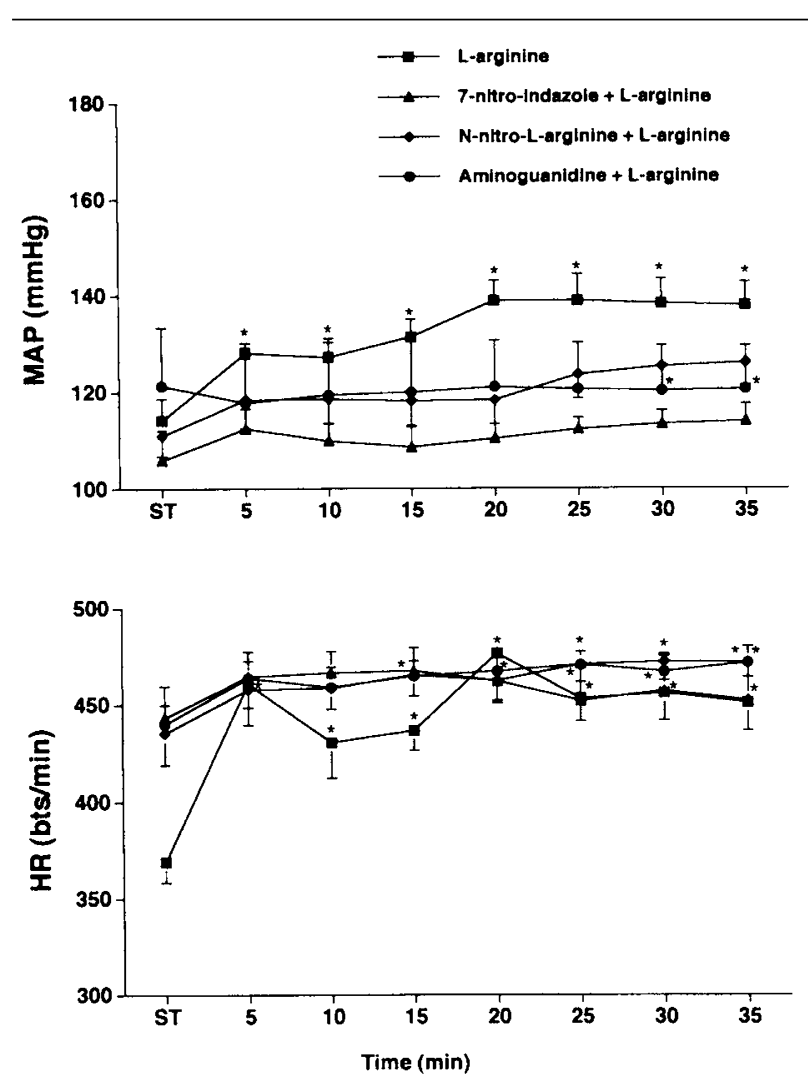

FIGURE 4 Mean arterial blood pressure and heart rate changes following L-arginine alone $(n=8), 7$-nitro indazole $(n=8)$, N-nitroL-arginine $(n=8)$ and aminoguanidine $(n=8)$ in L-arginine treated rats subjected to formalin injection. Data are expressed as actual changes from steady state $(\mathrm{ST}$; mean $\pm \mathrm{SEM}) .{ }^{*} \mathrm{P}<0.05$ vs $\mathrm{ST}$.

30 and $35 \mathrm{~min}$ (phase 2). In contrast, the pressor effect induced by formalin administration in phase 1 was abolished following $\mathrm{N}$-nitro-L-arginine, aminoguanidine and 7-nitro-indazole. Although MAP remained unchanged in response to $\mathrm{N}$-nitro- $\mathrm{L}$-arginine, the pressor effects induced by formalin were inhibited in the presence of aminoguanidine at $20 \mathrm{~min}$ by $54 \%$ and in the presence of 7 -nitro indazole during phase 2. Furthermore, formalin administration induced a significant increase in HR in phase 1 by $15 \%$ and in phase 2 by $25 \%$. The changes in HR were similar to those observed on MAP. The tachycardia induced in response to formalin administration was abolished in animals treated with $\mathrm{N}$-nitro-L-arginine, aminoguanidine and 7-nitro-L-arginine during phase 1. The formalin-induced tachycardia was significantly decreased at $20 \mathrm{~min}$ by $50 \%$ following the administration of aminoguanidine and at $25 \mathrm{~min}$ by $57 \%$ following the administration of $\mathrm{N}$-nitro-L-arginine. As 
compared to control saline, the magnitude in the formalin-induced tachycardia was inhibited in the presence of aminoguanidine and $\mathrm{N}$-nitro- $\mathrm{L}$-arginine during phase 2 .

In animals pretreated with L-arginine, the pressor effects induced by formalin administration were abolished in the presence of $\mathrm{N}$-nitro-L-arginine, 7-nitro indazole and aminoguanidine during phase $\mathrm{l}$ and phase 2. However, a delayed increase in BP was recorded at 30 and $35 \mathrm{~min}$ in the presence of N-nitroL-arginine. Our data also show that the formalininduced tachycardia was significantly decreased at 15 min by $60 \%$, at $20 \mathrm{~min}$ by $74 \%$, at $25 \mathrm{~min}$ by $63 \%$, at $30 \mathrm{~min}$ by $68 \%$ and at $35 \mathrm{~min}$ by $61 \%$ following aminoguanidine administration during phase 2 . Furthermore, the formalin-induced tachycardia was significantly decreased at $20 \mathrm{~min}$ by $74 \%$ and at 25 min by $56 \%$ following the administration of N-nitroL-arginine during phase 2 (Figure 4 ).

Phenylephrine administered iv in a dose of 50 $\mu \mathrm{g} \cdot \mathrm{kg}^{-1} \cdot \mathrm{min}^{-1}$ in rats subjected to formalin administration significantly elevated $\mathrm{BP}(30 \pm 4 \mathrm{mmHg})$. The onset of the effect was more rapid than following $\mathrm{N}$ nitro-L-arginine, but the magnitude of the peak effect and its duration was similar to the pressor effect of $\mathrm{N}$ nitro-L-arginine. However, this dose of phenylephrine did not have any effect on nociception or motor performance in five rats tested (data not shown).

\section{Edema formation}

Our data demonstrate that the paw injected with formalin was $4 \pm 1 \mathrm{~mm}$ larger than the non-injected paw. Paw edema remained unchanged in animals treated with $\mathrm{N}$-nitro-L-arginine and 7-nitro indazole whereas paw edema was significantly reduced in aminoguanidine-treated animals $(2 \pm 1$ vs $4 \pm 1 \mathrm{~mm})$.

\section{Discussion}

We investigated the role of peripheral NO using specific inhibitors of constitutive (endothelial and neuronal) and inducible NOS in the modulation of pain and associated cardiovascular properties in awake rats subjected to the formalin test. To differentiate between sedation, inadequate anesthesia and analgesic properties of NOS inhibitors, our study has been conducted in awake free-moving rats. Although we did not perform specific motor and somatosensory testing, animals appeared to maintain normal behaviour before and during saline, $\mathrm{N}$-nitro-L-arginine, 7-nitro indazole and aminoguanidine administrations.

Blockade of NOS by $\mathrm{N}$-nitro-L-arginine reduced the paw lifting time recorded immediately after the formalin administration (phase 1). While the nocicep- tive responses to peripheral administration of formalin can be modulated by inhibitors of the synthesis of $\mathrm{NO}$, they can also be increased by L-arginine, a precursor of the synthesis of NO. As a result, our data show that the inhibitory effects induced by $\mathrm{N}$-nitro-Larginine on paw lifting time could be reversed by Larginine, suggesting that the constitutive NOS enzyme is involved in the $\mathrm{NO}$ generation occurring in the early phase following formalin administration. In contrast, the administration of 7-nitro indazole, a specific neuronal NOS inhibitor did not induce any significant changes on phase 1 in response to formalin administration indicating that neuronal NOS plays a minor role in the modulation of pain in the initial phase of the formalin test.

An important aspect of this work is that we have also studied the possible involvement of inducible NOS in the generation of NO in acute pain modulation in rats subjected to the formalin test. Consequently, compounds that selectively inhibit inducible NOS and scavenge peroxynitrite such as aminoguanidine have been shown to exert antiinflammatory/permeability effects in various experimental models. ${ }^{21,22}$ Our data demonstrate that aminoguanidine response on paw lifting time remains unchanged in phase 1 in animals subjected to the formalin test. Therefore, the lack of significant effects of aminoguanidine during phase 1 may be considered as evidence that inducible NOS does not contribute to the modulation of pain behaviours in the initial phase of the formalin test.

As compared to phase 1 , our data show that all three studied NOS inhibitors, i.e., N-nitro-L-arginine, 7 -nitro-indazole and aminoguanidine were effective in decreasing paw lifting time during phase 2. Our data demonstrate that L-arginine also reversed the $\mathrm{N}$-nitroL-arginine-induced inhibitory behaviour effects in phase 2, but further decreased paw lifting time induced by 7 -nitro indazole and aminoguanidine in phase 1 and phase 2. Accordingly, our data indicate that endothelial NOS remains the only isoform involved in phases 1 and 2 in response to formalin injection. Furthermore, our data suggest that neuronal and inducible NOS isoforms induced indirect inhibitory pain behaviours responses likely through a non-specific NO pathway. Although our findings parallelled those reported by Allawi et al. ${ }^{23}$ suggesting that 7-nitro indazole exerted effects in the periphery which were unrelated to neuronal NOS blockade, they contrast data previously reported by Hao et al. ${ }^{24}$ in spinally injured rats. The reason for the discrepancy between those two studies is not clear although it may reflect differences in nociceptive stimulus or in the 
NOS inhibitor used. Our data also indicate that the inhibitory behaviour effects of $\mathrm{N}$-nitro-L-arginine and 7-nitro indazole in phase 2 are not secondary to an anti-edema action because $\mathrm{N}$-nitro-L-arginine and 7nitro indazole failed to prevent paw edema following formalin injection. In contrast, aminoguanidine significantly decreased paw edema in response to formalin administration, supporting previous data reported in carrageenan-induced hyperalgesia in rats. ${ }^{25}$ Thus, it may be hypothesized that formalin administration causes cytotoxicity at least in part through peroxynitrite production during inflammation. ${ }^{26,27}$ Peroxynitrite production has been previously reported in animals subjected to dextran or carrageenaninduced acute inflammation. ${ }^{28}$ Therefore, our data indicate that aminoguanidine exhibits antinociceptive activity in the formalin model secondary to an antiinflammatory effect, suggesting that the anti-inflammatory effects induced by aminoguanidine may be related to an inhibition of the expression/activity of the inducible NOS and/or to oxyradical and peroxynitrite scavenging. However, additional in vivo experiments are required to further examine the contribution of inducible NOS in the modulation of pain in animals subjected to the formalin test.

In addition to lifting behaviours, the formalin stimulus induced increases in BP and HR. These findings link those previously described by Yoon et al..$^{29}$ Despite inhibition of paw lifting time, NOS inhibitors affected differently the associated increases in BP and HR in awake rats subjected to the formalin administration. Although all NOS inhibitors inhibited the initial tachycardia (phase 1), they had little effect on the increase in HR observed during phase 2 following formalin administration. Similarly, the pressor effects induced by formalin administration were inhibited by all three NOS inhibitors during phase 1 while the pressor effects induced by formalin were inhibited by only one NOS inhibitor, 7-nitro indazole during phase 2. However, prior to formalin administration, $\mathrm{N}$-nitro-L-arginine induced a significant increase in MAP, suggesting endothelial NOS inhibition. ${ }^{30}$ In order to exclude the possibility that the effects of $\mathrm{N}$ nitro-L-arginine on $\mathrm{BP}$ were related to an analgesic effect, the effects of phenylephrine, an $\alpha_{1}$-adrenoceptor agonist were also examined. Phenylephrine increased the systemic BP to a similar extent as $\mathrm{N}$ nitro-L-arginine, but failed to relieve pain behaviour.

At doses of NOS inhibitors used which produce pronounced antinociceptive activity, no changes in animal behaviours were observed or could be detected. Furthermore, no reduction in locomotor activity was apparent. Thus, at doses within the antinocicep- tive range, all NOS inhibitors used in this study have no detectable sedative or other behavioural effects that might contribute to their antinociceptive effect.

In conclusion, we have reported that endothelial NOS isoform plays a crucial role in phase 1 and in phase 2 whereas neuronal and inducible NOS isoforms modulate pain behaviours through a non-NO related pathway. In addition, our data also suggest that aminoguanidine is likely to exhibit antinociception through an anti-inflammatory effect. Therefore, our data provide direct evidence of the involvement of $\mathrm{NO}$ in the modulation of pain and some of the associated cardiovascular changes that have been shown to be independent of nociceptive behaviour and directly related to the level of the pain stimuli. However, further studies to clarify the role of the NO pathway in chronic hyperalgesia are warranted.

\section{References}

1 Garthwaite J, Charles SL, Chess-Williams R. Endothelium-derived relaxing factor release on activation of NMDA receptors suggests role as intercellular messenger in brain. Nature 1988; 336: 385-8.

2 Moore PK, Oluyomi AO, Babbedge RC, Wallace P, Hart $S L$. L-N ${ }^{\mathrm{G}}$-nitro arginine methyl ester exhibits antinociceptive activity in the mouse. Br J Pharmacol 1991; 102: 198-202.

3 Abbott FV, Franklin KB, Westbrook RF. The formalin test: scoring properties of the first and second phases of the pain response in rats. Pain 1995; 60: 91-102.

4 Taylor BK, Peterson MA, Basbaum AI. Persistent cardiovascular and behavioral nociceptive responses to subcutaneous formalin require peripheral nerve input. J Neuroscience 1995; 15: 7575-84.

5 Tjolsen A, Berge OG, Hunskaar S, Rosland JH, Hole K. The formalin test: an evaluation of the method. Pain 1992; 51: 5-17.

6 Hunskaar $S$, Hole $K$. The formalin test in mice: dissocation between inflammatory and non-inflammatory pain. Pain 1987; 30: 103-14.

7 Coderre TJ, Vaccarino AL, Melzack R. Central nervous system plasticity in the tonic pain response to subcutaneous formalin injection. Brain Res 1990; 535: 155-8.

8 Dubuisson D, Dennis $S G$. The formalin test: a quantitative study of the analgesic effects of morphine, meperidine, and brainstem stimulation in rats and cats. Pain 1977; 4: 161-74.

9 Haley JE, Dickenson AH, Schachter M. Electrophysiological evidence for a role of nitric oxide in prolonged chemical nociception in the rat. Neuropharmacology 1992; 31: 251-8.

10 Goettl VM, Larson AA. Nitric oxide mediates longterm hyperalgesic and antinociceptive effects of the $\mathrm{N}$ - 
terminus of substance $\mathrm{P}$ in the formalin assay in mice. Pain 1996; 67: 435-41.

11 Malmberg $A B$, Yaksh TL. Spinal nitric oxide synthesis inhibition blocks NMDA-induced thermal hyperalgesia and produces antinociception in the formalin test in rats. Pain 1993; 54: 291-300.

12 Meller ST, Gebhart GF. Nitric oxide (NO) and nociceptive processing in the spinal cord. Pain 1993; 521: 127-36.

13 Meller ST, Pechman PS, Gebhart GF, Maves TJ. Nitric oxide mediates the thermal hyperalgesia produced in a model of neuropathic pain in the rat. Neuroscience 1992; 50: 7-10.

14 Verge VM, Xu Z, Xu XJ, Wiesenfeld-Hallin Z, Hokfelt $T$. Marked increase in nitric synthase mRNA in rat dorsal root ganglia after peripheral axotomy: in situ hybridization and functional studies. Proc Natl Acad Sci USA 1992; 89: 11617-21.

15 Semos $M L$, Headley PM. The role of nitric oxide in spinal nociceptive reflexes in rats with neurogenic and non-neurogenic peripheral inflammation. Neuropharmacology 1994; 33: 1487-97.

16 Alderton WK, Cooper CE, Knowles RG. Nitric oxide synthases: structure, function and inhibition. Biochem J 2001; 357: 593-615.

17 Gardiner SM, Compton AM, Kemp PA, Bennett T. Regional and cardiac haemodynamic effects of $\mathrm{N}^{\mathrm{G}_{-}}$ nitro-L-arginine methyl ester in conscious, Long Evans rats. Br J Pharmacol 1990; 101: 625-31.

18 Joly GA, Ayres M, Chelly F, Kilbourn RG. Effects of $\mathrm{N}^{\mathrm{G}}$-methyl-L-arginine, $\mathrm{N}^{\mathrm{G}}$-nitro-L-arginine, and aminoguanidine on constitutive and inducible nitric oxide synthase in rat aorta. Biochem Biophys Res Commun 1994; 199: 147-54.

19 Moore PK, Wallace P, Gaffen Z, Hart SL, Babbedge RC. Characterization of the novel nitric oxide synthase inhibitor 7-nitro indazole and related indazoles: antinociceptive and cardiovascular effects. $\mathrm{Br} \mathrm{J}$ Pharmacol 1993; 110: 219-24.

20 Eschalier A, Kayser V, Guilband G. Influence of a specific $5-\mathrm{HT}_{3}$ antagonist on carrageenan-induced hyperalgesia in rats. Pain 1989; 36: 249-55.

21 Szabo C, Ferrer-Sueta G, Zingarelli B, Southan GJ, Salzman AL, Radi R. Mercaptoethylguanidine and guanidine inhibitors of nitric-oxide synthase react with peroxynitrite and protect against peroxynitrite-induced oxidative damage. J Biol Chem 1997; 272: 9030-6.

22 Doursout MF, Kilbourn RG, Hartley CJ, Chelly JE. Comparison of responses to aminoguanidine and $\mathrm{N}$ methyl-L-arginine in a porcine endotoxin shock model. In: Moncada S, Toda N, Maeda H, Higgs EA (Eds.). The Biology of Nitric Oxide, Part 6. London: Portland Press Proceedings; 1998: 219.
23 Allawi HS, Wallace P, Pitcher A, Gaffen Z, Bland-Ward $P A$, Moore $P K$. Effect of 7-nitro indazole on neurotransmission in the rat vas deferens: mechanisms unrelated to inhibition of nitric oxide synthase. $\mathrm{Br} \mathrm{J}$ Pharmacol 1994; 113: 282-8.

24 Hao JX, Xu XJ. Treatment of a chronic allodynia-like response in spinally injured rats: effects of systemically administered nitric oxide synthase inhibitors. Pain 1996; 66: 313-9.

25 Duarte ID, Lorenzetti BB, Ferreira SH. Peripheral analgesia and activation of the nitric oxide-cyclic GMP pathway. Eur J Pharmacol 1990; 186: 289-93.

26 Ischiropoulous H, Zhu L, Beckman JS. Peroxynitrite formation from macrophage-derived nitric oxide. Arch Biochem Biophys 1992; 298: 446-51.

27 Beckman JS, Ischiropoulos H, Zhu L, et al. Kinetics of superoxide dismutase- and iron-catalyzed nitration of phenolics by peroxynitrite. Arch Biochem Biophys 1992; 298: 438-45.

28 Cuzzocrea S, Zingarelli B, Calapai G, Nava F, Caputi $A$. Zymosan-activated plasma induces paw oedema by nitric oxide and prostaglandin production. Life Sci 1997; 60: 215-20.

29 roon MH, Yaksh TL. The effect of intrathecal gabapentin on pain behavior and hemodyanmics on the formalin test in the rat. Anesth Analg 1999; 89: 434-9.

30 Rees DD, Palmer RM, Schulz R, Hodson HF, Moncada $S$. Characterization of three inhibitors of endothelial nitric oxide synthase in vitro and in vivo. $\mathrm{Br} \mathrm{J}$ Pharmacol 1990; 101: 746-52. 